\title{
O batismo cristão à luz da passagem material ${ }^{1}$
}

\author{
The Christian baptism in the lights of the material passage
}

Éder Beling ${ }^{2}$

\section{RESUMO}

Neste artigo, se colocam à prova duas hipóteses. A nossa primeira hipótese baseia-se no fato de que a intencionalidade fundamental do batismo cristão é agregar um novo membro à comunidade eclesiástica. Ou, à luz da intuição base de Van Gennep sobre a relação existente entre as passagens rituais e as passagens materiais, o ritual do batismo cristão deve ser elaborado a partir da dimensão espacial e esta deve deixar as suas marcas. Nossa segunda hipótese é a seguinte: as novas condições socioculturais que emergiram na Idade Média provocaram o encolhimento da passagem material no seio do ritual do batismo, porque causaram o desaparecimento da diferença social entre o "interior" e o "exterior" ou entre "nós" e os "outros". Assim, em uma situação de hegemonia religiosa, a sociedade no seu todo torna-se sagrada novamente. Portanto, desaparece a necessidade de ritualização da passagem material do "paganismo" à "fé". Em conclusão, nós iremos tentar mostrar a relevância da nossa aproximação histórica e ritual para os temas da atualidade.

Palavras-chave: Batismo. Passagem Material. Catolicismo. Lutero.

\section{ABSTRACT}

In this paper, two hypotheses will be tested. Our first hypothesis is based on Van Gennep's basic intuition about the relationship between ritual passages and material passages, the ritual of Christian baptism must have been elaborated from the spatial dimension and this must have left its marks. Our second hypothesis is that the new sociocultural conditions that emerged in Middle Age caused the narrowing of the material passage within the ritual of baptism because the disappearance of the social difference between the "inside" and the "outside" or between "us" and "others". Indeed, in a situation of religious hegemony, the whole society becomes sacred again. Thus, the need to ritualize the passage from "paganism" to "faith" also disappears. In conclusion, we will try to show the relevance of our historical and ritual approach to current issues.

Keywords: Baptism. Material passage. Catholicism. Luther.

\footnotetext{
${ }^{1}$ Recebido em 01/11/2017. Aprovado em 31/12/2017.

2 Doutorando em Teologia pela Faculdades EST, São Leopoldo/RS. E-mail: ederbeling@gmail.com.
} 


\section{Introdução}

O título deste artigo é sugestivo ao tema que se pretende abordar. A partir da leitura de Arnold van Gennep, em seu livro "Os ritos de passagem", a passagem material ocupa um dos primeiros capítulos do trabalho e é caracterizada como um dos três pontos importantes da obra. Por um lado, a discussão que ele faz possui uma importante função para a compreensão dos ritos. Por outro lado, desde um ponto de vista contemporâneo, autores criticam a falta de discussão espacial na maioria dos escritos acadêmicos. Nesse sentido, é preciso acentuar a primazia de Gennep em trazer tal discussão no capítulo inicial de seu livro.

A questão do espaço é importante para este artigo, pois tudo o que o ser humano realiza encontra-se inserido dentro do binômio espaço-tempo. Fundamentalmente, o conceito de espaço-tempo perpassa toda e qualquer pesquisa científica, vivência e/ ou experiência humana (TUAN, 1983, p. 3. MESLIN, 1992, p. 116. CASSIRER, 1972, p. 75), ${ }_{1}^{3}$ ou seja, o ser humano é um ser temporal e espacial. Essas duas categorias estão intimamente vinculadas à vida dele.

Dessa forma, tem-se como importante a relação do ser humano com o espaço. Entre os vários ritos práticos no âmbito da igreja cristã, abordar-se-á o batismo, pois este é um de seus ritos mais importantes. Além de ser considerado sacramento pelas igrejas cristãs, é o rito de iniciação/entrada dos fiéis à comunidade de fé.

Quer-se colocar à prova duas hipóteses. A primeira hipótese é baseada no fato de que a intencionalidade fundamental do batismo cristão é agregar um novo membro para a comunidade eclesial - iniciação cristã, catecumenato são alguns nomes usadas para expressar a passagem ou partes do rito de passagem à comunidade eclesial -. Dentro da iniciação, à luz da intuição básica de Gennep sobre os ritos de passagem, mas sobretudo, a partir da passagem material, o ritual do batismo cristão deve ter sido elaborado também a partir da dimensão espacial e, portanto, deve ter deixado as suas marcas no rito.

\footnotetext{
3 Tuan $(1983$, p. 3) afirma que "tempo e lugar são componentes básicos do mundo vivido, nós os admitimos como certos". Lugar aqui como espaço onde se dão as experiências e vivencias do ser humano. E Cassirer $(1972$, p. 75) afirma que "O espaço e o tempo são o arcabouço que sustenta toda realidade. Não podemos conceber coisa alguma real senão sob as condições do espaço e do tempo".
} 
A segunda hipótese tem como base o "reducionismo" ou a "renovação litúrgica" da prática batismal a partir do Idade Média, em especial, no período da Reforma Protestante. As novas condições socioculturais surgidas na Idade Média acarretaram uma mudança de paradigma na realização do rito de iniciação/batismo. A sociedade como um todo era sagrada, não havia diferença entre o "interior" e "exterior", ou entre os que são "pagãos", ou que têm "fé", ou entre "Igreja" e "Estado". Essa situação também provoca mudanças na execução do rito e em sua relação com o espaço. A sequência ritual ou o ordo litúrgico do rito batismal passa por alteração. Em nossa intuição, isso altera a forma como se relaciona o rito com o espaço. $\bigcirc$ principal questionamento encontra-se sobre esse ponto.

\section{A passagem material}

Com a passagem material, Gennep introduz o importante questionamento espacial em seu trabalho. O debate acerca do conceito espacial em seu trabalho retoma tipologias de civilizações e povos nos quais aparece o elemento "mágicoreligioso", categoria que define cientificamente o estudo, ou seja, a relação dos ritos dinâmicos ou animistas que constituem a religião e que pode ser observado nos ritos de diferentes civilizações, culturas e religiões (GENNEP, 2011, p. 31).

O caráter mágico-religioso funda-se sobre a separação entre o sagrado e o profano. A passagem material representa o descolamento que o ser humano faz dentro do espaço, que pode ser tanto um espaço sagrado quanto profano. Gennep (2011, p. 31) cita o exemplo de um homem que vive em uma tribo (local sagrado) e, a partir do momento em que ele sai da tribo e torna-se estrangeiro, encontra-se no espaço profano. Nesse exemplo de Gennep (2011, p. 31), a passagem material, isto é, uma categoria espacial, afirma o valor da categoria do sagrado, que "de fato, não é um valor absoluto, mas um valor que indica situações respectivas", ou seja, é um valor relacional e vivencial e se encontra profundamente entrelaçado com a categoria espacial. Além dessa passagem, há as que contêm interdições de caráter político, jurídico e econômico [GENNEP, 2011, p. 33).

As interdições mágico-religiosas não se aplicam somente ao país ou ao território, mas também à aldeia, cidade, quarteirão, templo ou casa (GENNEP, 2011, 
p. 36). Nesses exemplos, o "limite é marcado por um objeto, poste, pórtico, uma pedra em pé (marco, termo etc.)" (GENNEP, 2011, p. 33), precedido ou acompanhado de um rito de consagração do espaço à divindade. Ao movimento de passagem de um lugar para o outro, com caráter mágico-religioso atribui-se o nome de "margem" ou limem, que seria ao mesmo tempo "ideal e material", e se encontra "mais ou menos pronunciada, em todas as cerimonias que acompanham a passagem de uma situação mágico-religiosa ou social à outra" (GENNEP, 2011, p. 35).

A teoria de Gennep sofre de uma carência. $\bigcirc$ fato de iniciar com a passagem material demonstra a importância do tema, como ele mesmo afirma ao concluir o livro. A passagem material é o terceiro ponto importante dentro da teoria dos ritos de passagem, pois ela ajuda a manter e criar uma "identidade da passagem através das diversas situações sociais" (GENNEP, 2011, p. 162). Contudo, a pesquisa foca nos questionamentos ligados à natureza geral do rito, ou seja, os ritos em "sua significação essencial e sua situação relativa no conjunto das cerimônias e sua sequência" (GENNEP, 2011, p. 162).

Sendo assim, a passagem material - ao mesmo tempo percebida como importante - não ganha um desenvolvimento conceitual em seu trabalho, não havendo uma teoria significativa sobre ela, estando a categoria espacial ou da passagem material dispersa ao longo de seu estudo. Uma crítica feita por Mauss vai na direção do que foi afirmado. Para ele, a escola sociológica de Gennep fazia uso de um grande número de exemplos em seus métodos, sem se atentar a utilizar um número mínimo de exemplos que poderiam deixar a análise mais precisa. $\mathrm{A}$ pesquisa de Gennep foi considerada por Mauss (1902, p. 202) como "uma espécie de passeio por toda a história e a etnografia" ${ }^{\prime 4}$. Por outro lado, o conceito de espaço se encontra, de uma forma ou de outra, inserido no âmbito da discussão como uma linguagem não verbal que se integra e faz parte do âmbito do rito.

Outro questionamento que se levanta é: qual é o entendimento de espaço? O entendimento de espaço deve ir além de uma qualidade material exterior ao ser humano, o próprio ser humano deve ser entendido como uma qualidade material.

4 “[...] une sorte de randonnée à travers toute l'histoire et toute l'ethnographie". MAUSS, Marcel. Review of Les Rites de Passage. L'année Sociologique, Paris, v. 11, p. 200-202, 1909. p. 202. (Tradução nossa). 
Sua vivência e sua experiência no e com o espaço deve ser entendida como tendo significação espacial, onde o próprio corpo do ser humano é entendido como parte da passagem material. Em Gennep (GENNEP, 2011, p. 37), percebe-se que apenas o espaço físico possui importância, por isso, o autor apenas foca nos exemplos de margem que apresenta no capítulo sobre a "passagem material".

Gennep não representa um avanço no que se trata da discussão do conceito espacial. $\bigcirc$ conceito de espaço que havia em sua época baseava-se na separação do espaço a partir de conceituações matemático-físicas - o que, inevitavelmente, traz e trouxe consigo novas formulações de cosmovisões - e uma redução de espaço e lugar a um mero formalismo matemático-físico (WERTHEIM, 2001, p. 138). Mesmo na atualidade, o conceito de espaço ainda não recebeu sua devida atenção, sobretudo, no âmbito ritual das igrejas cristãs, essa é a crítica de Lukken (2005, p. 117). Ele critica o fato de normalmente não se levar em consideração o aspecto espacial no rito litúrgico das igrejas cristãs ${ }^{5}$.

Alguns autores se enveredaram e discutiram a conceituação de espaço. Tuan (1983, p. 39), na década de 60, descreveu o conceito de espaço da seguinte maneira:

'Espaço' é um termo abstrato para um conjunto complexo de ideias. Pessoas de diferentes culturas diferem na forma de dividir seu mundo, de atribuir valores às suas partes e de medi-las. [...] existem certas semelhanças culturais comuns, e elas repousam basicamente no fato de que o homem [ser humano] é a medida de todas as coisas. [...] O homem [ser humano], como resultado de sua experiência íntima com seu corpo e com outras pessoas, organiza o espaço a fim de conformá-lo a suas necessidades biológicas e relações sociais.

Igualmente, a arquitetura se encontra profundamente relacionada com o espaço e ajuda a compreender melhor de que forma acontece o ritual. Ela é em si mesma parte da característica essencial do espaço e do ritual. Por isso, ao nos referirmos à arquitetura dos lugares de batismo, não nos referimos somente às características da construção como a forma, o plano arquitetônico e a estrutura, mas

5 "We normally speak of ritual without taking space into account." LUKKEN, Gerard. Rituals in abundance. critical reflections on the place, form, and identity of Christian ritual in our culture. Leuven: Peeters, 2005. p. 117. 
também à arte, ao ambiente do batismo, ao seu espaço litúrgico, "a estética, a iconografia, os utensílios, a ornamentação, a cor das vestes e dos paramentos e os materiais de construção"6 (STAUFFER, 1994, p. 167).

À luz da discussão sociológica moderna sobre o espaço, pode-se entendê-lo não apenas como uma dimensão na qual o ser humano vive, mas também na qual o ser humano se relaciona. $\bigcirc$ espaço é definido da seguinte forma pela socióloga Martina Löw $(2015,224):$ "o espaço é uma disposição e uma ordenação relacional dos bens sociais e humanos (organismo) nos lugares" ${ }^{\prime \prime}$. $\bigcirc$ acento recai não tanto sobre os bens materiais, mas sobre os bens sociais e simbólicos que se relacionam nos lugares, que encontram lugar na disposição espacial e no ordenamento espacial em conjunto com as ações humanas. Na conceituação de espaço está intrínseca a presença do ser humano, ora como componente do espaço - como um elemento de ligação -, ora relacionado através das atividades humanas (LÖW, 2015, p. 224) ${ }^{8}$, além de outras formas. Ademais, o lugar, quando relacionado com outro lugar, produz espaço.

Por se tratar de um processo, a disposição deixa-se diferenciar sob dois aspetos analíticos distintos: Syntheseleistung e Spacing. $\bigcirc$ primeiro, Syntheseleistung, refere-se à reunião de bens sociais e pessoas como elementos, isso porque o espaço não é um bem constituído, mas um bem em constante capacidade de (re)produzir síntese, através das ideias, memórias e percepções. Já Spacing encontra-se em contraposição à Syntheseleistung, sendo a capacidade de situar "a si-mesmo, a construção, edificar e medir, além de, sobretudo, situar marcações simbólicas, para

\footnotetext{
6 "[...] la estética, la iconografía, los utensilios, la ornamentación, el color de las vestiduras y paramentos, y los materiales de construcción." STAUFFER, S. Anita. Problemática contemporánea de la arquitectura eclesial e la cultura. In: STAUFFER, S. Anita (Ed.). Dialogo entre culto y cultura. Ginebra: Federación Luterana Mundial, 1994. p. 167. (Tradução nossa).

7 "Raum ist eine relationale (An)Ordnung sozialer Güter und Menschen (Lebewesen) an Orten." LÖW, Martina. Raumsoziologie. 8. Auflage. Frankfurt am Main: Suhrkamp, 2015. p. 224. (Grifo da autora/ Tradução nossa).

8 "Menschen sind in die Konstitution von Raum in zweifacher Hinsicht einbezogen. Zum einen können sie ein Bestandteil der zu Raum verknüpften Elemente sein, zum zweiten ist die Verknüpfung selbst an menschliche Aktivität gebunden." (LÖW, 2015, p. 224).
} 
tornar conhecível o conjunto dos bens e pessoas" ${ }^{\prime \prime 9}$ (LÖW, 2015, p. 225) e situar as informações.

Os dois conceitos encontram-se relacionados através da ação, pois ambos estão conectados e situados por ela. Essa relação entre ambos os conceitos forma uma dualidade do espaço (LÖW, 2015, p. 226). É essa dualidade que constantemente promoverá a conexão entre os termos Syntheseleistung e Spacing, mantendo e criando novas formas espaciais através das ações humanas e sua relação de síntese com os lugares. Pois, os bens sociais e os seres humanos possuem uma qualidade material e simbólica que se transmite e se relaciona no espaço, criando diferentes atmosferas que são sempre novamente percebidas e sintetizadas através destes processos (LÖW, 2015, p. 228-229).

Essa constante capacidade de relação, síntese e simbolização apresenta-se fortemente nos lugares sagrados, sejam eles uma igreja, um cemitério, batistério etc. Por isso, pode-se afirmar que os lugares sagrados e consagrados para finalidades religiosas representam "a experiência do sagrado" $\left(\mathrm{BUSCH}, 2010\right.$, p. 53) ${ }^{10}$, pois "neles personificam-se não somente momentos de religiosidade, mas eles dão vivência à presença do divino" (BUSCH, 2010, p. 53)", posto que, "a força dos espaços sagrados encontra-se justamente no fato de eles tornarem 0 transcendente experienciável" (BUSCH, 2010, p. 53) os lugares podem ser compreendidos como "textos" (BIERITZ, 2011, p. 144) que podem ser lidos e nos quais ocorre uma sintopia com o divino.

Para Bieritz, essa forma de entender o espaço também passa pela percepção da memória, pois:

\footnotetext{
9 "Diese Plazierungsprozesse, das heißt, das Plazieren sozialer Güter oder Lebewesen bzw. das SichPlazieren derselben, das Bauen, Errichten oder Vermessen, aus das Positionieren primär symbolische kenntliche zu machen, das Plazieren von Informationen werden als Spacing bezeichnet." (LÖW, 2015, p. 225). (Tradução nossa).

10 "[...] die Erfahrung des Heiligen [...]". BUSCH, Kathrin. Kraft der Räume. In: ERNE, Thomas; SCHÜZ, Peter. Die Religion des Raumes und die Räumlichkeit der Religion. Göttingen: Vandenhoeck \& Ruprecht, 2010. p. 53. (Tradução nossa).

" "In ihnen verkörpern sich nicht lediglich Momente von Religiosität, sondern sie machen die Anwesenheit von Göttlichen erlebbar". BUSCH, 2010, p. 53. (Tradução nossa).

12 "Die Kraft der sakralen Räume besteht darin, Transzendenz erfahrbar zu machen". (BUSCH, 2010, p. 53). (Tradução nossa).
} 
Memórias trazem frequentemente consigo aromas, sons, ânimos, um sabor especial. Isto é: eles não são apenas produtos do pensamento. Eles estão registrados em nosso corpo. E eles têm o seu lugar e o seu tempo. E isto vale também lá, onde ambos, ainda que só vagamente são palpáveis, como atmosfera talvez, que se eleva juntamente com as imagens da memória, as envolve e sustenta. Não-espacial e atemporal, as memórias não podem $\operatorname{ser}^{13}$.

Smith, ao discorrer sobre as tradições do povo Arandan, expressa que, para eles, o espaço sagrado/significativo é aquele no qual ocorreu uma atividade ancestral. Através da narrativa mítica, tal espaço é demarcado por algum objeto e será local de rememoração de um feito mítico e sagrado. Em consequência disso, para este povo, “a especificidade do lugar é o que é rememorado, o que dá origem e o que é perpetuado no memorial ${ }^{m / 4}$ (SMITH, 1984, p. 22). Ademais, o espaço e o tempo também estão relacionados através da rememoração das experiências. Portanto, "assim é com a memória: é uma experiência complexa e ilusória. Parece ser preeminentemente uma questão do passado, mas é tanto mais um relacionamento com o presente. Parece ser preeminentemente uma questão de tempo, mas é tanto mais uma questão de espaço'”5 ${ }^{\prime \prime}$ (SMITH, 1984, p. 25).

A memória é um componente dos lugares e espaços. Para Assman [1999, p. 158), desde as técnicas mais antigas que há para se guardar fatos históricos, como textos em pedras, papiros, pinturas ou mosaicos, o espaço também é uma forma de guardar memória. $\bigcirc$ centro dessa técnica mnemônica é construído sobre duas bases: imagens e lugar. Imagens são uma codificação do conteúdo da memória em concisas

13 “Erinnerungen führen häufig spezifische Gerüche mit sich, Klänge, Stimmungen, einen besonderen Geschmack. Das heißt: Sie sind nicht nur Gedankengebilde. Sie sind unserem Körper eingeschrieben. Und sie haben ihren Ort und ihre Zeit. Das gilt auch dort, wo beides nur noch vage fassbar ist, als Atmosphäre vielleicht, die zusammen mit den Erinnerungs-Bildern aufsteigt, sie umhüllt und trägt. Ortlos, zeitlos kann Erinnerung nie sein." BIERITZ, Karl-Heinrich. Gedächtnis des Glaubens. Das Kirchenjahr vor den Herausforderungen der Gegenwart. Vortrag von Herrn Prof. Dr. Karl Heinrich Bieritz am 13. November 2009 im Religionspädagogisches Institut Loccum während des „Treffpunkt Kirchenpädagogik ${ }^{\prime \prime}$ gehalten. Disponível em: <http://www.rpi-loccum.de/material/audiovortraegel?page $=5>$. Acesso em 20 mai. 2014. (Grifo do autor). (Tradução nossa).

14 "[...] the specificity of place is what is remembered, is what gives rise to and is perpetuated in memorial." SMITH, Jonathan Z. To take place. toward theory of ritual. Chicago: University of Chicago Press, 1987. p. 22. (Tradução nossa).

15 " [...] so it is with memory: it is a complex and deceptive experience. It appears to be preeminently a matter of the past, yet it is as much an affair of the present. It appears to be preeminently a matter of time, yet it is as much an affair of space." (SMITH, 1987, p. 25). (Tradução nossa). 
formas imagéticas (imagens), e o lugar desempenha a função de atribuição dessas imagens em locais dentro de em um espaço estruturado. Forma-se, portanto, uma técnica mnemônica na qual o espaço é um meio (milieu), como uma construção ou um papel, e o símbolo torna-se aquilo que é rememorado.

O rito se encontra inserido nesse processo social, histórico, mnemônico e espacial acima descrito. Ele se entrelaça no âmbito do rito. Esse entrelaçamento é toda a vivência promovida no âmbito ritual, como processo que é de socialização e de quebra de paradigmas sociais ou a imposição deles, bem como a sua constante atualização e rememoração através da narrativa mítica e das disposições e sínteses espaciais. Aprofundando o conceito de rito e entrelaçando-o com os conceitos apresentados acima, busca-se em Lukken uma definição de rito. Para ele, a definição comporta pelo menos dez características diferentes, entretanto, segundo o autor, apenas dois aspectos são os mais importantes: a questão da repetição e da relação entre mito e rito, seguir-se-á apenas as duas percepções fundamentais.

a) Repetição: a base dos ritos está na apreensão dos símbolos, dos atos simbólicos e da linguagem simbólica. Os ritos se constituem no cotidiano da vida através da repetição de símbolos apreendidos, de atos simbólicos que dão a base da ritualização ao ser humano e que se expressam através da linguagem simbólica performática que já foram previamente dados. A importância da repetição dos ritos dá-se, pois eles possuem uma carga simbólica que se expressa por ela mesma, diferentemente de um signo. Mesmo que se tratem de rituais repetidos extensivas vezes ocorre uma comunicação significativa, ou seja, o ritual significa algo para quem o realiza e participa dele, pois somente a repetição promoverá o preenchimento de todas as lacunas, ajudando a manter a existência e a coerências humanas (LUKKEN, 2005, p. 38-50).

b) A relação entre rito e mito: o rito inclui em sua definição a linguagem simbólica, dessa forma, retoma-se a realidade última dentro do rito através da linguagem simbólica, ou seja, o mito entra no rito através da narrativa. Através da linguagem simbólica, o rito permite ao ser humano se conectar através de uma trama narrativa que envolve uma representação ritual através dos textos, sendo que o 
"ritual é uma práxis do dar sentido"16 (LUKKEN, 2005, p. 52). Somente na perfeita relação do sistema sensitivo humano é que pode acontecer o rito. $\bigcirc$ rito possui características sensitivo-simbólicas, e o mito uma característica narrativa, ambas estão interligadas através da performance simbólica do mito e da ação ritual (LUKKEN, 2005, p. 51-54). Além disso, a integração entre mito e rito dá ao espaço a função à qual ele é consagrado, pois se busca, através da autoridade narrativa do mito, evidenciar que o espaço consagrado possui ligação com a ação ritual desenvolvida.

A base construída até aqui poderia certamente ser expandida. Mas se deve retornar ao tema aqui proposto, isto é, a passagem material no âmbito do rito do batismo, a primeira hipótese deste trabalho. $\bigcirc$ espaço desempenha papel importante dentro do rito, como categoria que pode promover, através das formas simbólicas, rememoração e também síntese das ações humanas desempenhadas no lugar no qual ela ocorre, como no caso do rito. Não é possível diminuir ou mesmo atenuar que o espaço não desempenha nenhum papel na comunicação e simbolização da ação do ritual. Tendo em vista que tudo que foi elencado ocorre precisamente porque o rito não acontece em nenhum outro lugar que não seja em um espaço e em um lugar concreto, com ações simbólicas que são mediadas pela espacialidade em conjunto com a narrativa mítica e de processos perceptivos e mnemônicos. Nesse sentido, a água do batismo, juntamente com o rito, forma uma unidade ritual e é, portanto, uma forma de espacialização do rito, ou seja, é uma categoria que se liga ao conceito de passagem material, afirmando a primeira hipótese. Poder-se-ia dizer que o espaço não possui uma percepção explícita ao longo do rito, ele não é o conteúdo principal do rito do batismo, mas ele é percebido implicitamente, é componente que liga, dispõe (disposição espacial), sintetiza, ajuda a promover a ação e rememora. Ele é um meio, como expressa a palavra francesa milieu, que, em seu significado basal, expressa uma relação espacial.

\section{3. $O$ batismo cristão como rito de iniciação na Igreja Católica e na Reforma Protestante}

16 "The ritual is a praxis of giving meaning". (LUKKEN, 2005, p. 52). (Tradução nossa). 
Para Gennep (2011, p. 29-30; 91-92), um rito de iniciação possui três fases: rito de separação, margem e agregação e, entre eles, períodos liminares. Essas três fases formam o todo do rito de iniciação, que pode ser descrito como um período de separação da comunidade, por um período determinado, em um período liminar em que candidatos são iniciados e preparados através de diferentes ritos e costumes, ao passo que, no final, serão agregados completamente na vida comunitária com uma nova identidade e status (JOHNSON, 2007, p. XVII-XVIII). O rito do batismo é um rito de iniciação, ele incluiu em si a referência à passagem material que se dá através do período liminal e de margem ${ }^{17}$ (KARANT-NUNN, 1997, p. 44).

No exemplo do rito de iniciação ao cristianismo no livro de Gennep, ele utiliza a descrição do rito de L. Duchesne (1920) em "Les origenes du culte chretien". Buscou-se o mesmo o rito para ser detalhadamente apresentado neste trabalho. Da mesma forma, buscou-se na tradição protestante o rito batismal descrito por Martinho Lutero no âmbito da Reforma Protestante, entende-se que houve uma grande mudança de ideias e também de formas rituais nesse período. Lutero (1965a) publicou duas ordens de batismo, utilizaremos em larga medida a segunda, "The Order of Baptism Newly Revised" [Português: "O Manual do Batismo traduzido para o Alemão Revisado $\left.(1526)^{\prime \prime 1}\right]^{18}$. E, por fim, seguindo em nossa segunda hipótese do reducionismo ritual iremos comparar o rito batismal descrito por Duchesne com o descrito por Martinho Lutero.

\subsection{O rito batismal no âmbito católico}

rito batismal apresentado por Duchesne é uma compilação de três ordens batismais existentes entre os séculos VII e IX, usados pela igreja romana: o Ordo Baptismi, do período de Carlos Magno; o Sacramentário do Papa Adriano; e o

17 KARANT-NUNN, Susan C. The Reformation of Ritual: An Interpretation of Early Modern Germany. London/New York: Routledge, 1997. p. 44. Ela afirma: "[...] The traditional pattern was that the priest and the acolyte, clad in their vestments, went out to greet at the church door the infant on whose behalf baptism was sought. In keeping with the ancient instructions, the child was to be held precisely beyond the threshold, in larger churches presumably in the narthex or the galilee; baptism was quite literally a liminal transaction! The clergy positioned themselves just within the sanctuary, the sacred domain."

${ }^{18} \mathrm{Em}$ português o rito pode ser encontrado em: LUTERO, Martinho. O Manual do Batismo traduzido para o Alemão Revisado (1526). In: LUTERO, Martinho. Obras Selecionadas. vida em comunidade. v. 7. São Leopoldo: Sinodal; Porto Alegre: Concórdia; Canoas: Ulbra, 2016. 
Sacramentário Gelasiano. Abaixo descreveremos o rito de iniciação ao batismo conforme relatado pelo autor.

O rito de iniciação ao batismo inicia-se com o rito do catecumenato (DUCHESNE, 1920, p. 313-315). O rito destina-se às pessoas adultas. A igreja romana tinha como costume batizar adultos até o século $\mathrm{XV}$, mas, por volta do século VII, já se batizavam crianças (ALMEIDA, 2014, p. 4; MORAES, 2009, p. 152).
A entrada no catecumenato é acompanhada das seguintes cerimonias:
a exuflação, com uma fórmula de exorcismo;
o sinal da cruz na fronte;
a imposição do sal. ${ }^{19}$ (DUCHESNE, 1920, p. 313).

O convertido se apresenta diante do padre que faz exuflações com uma fórmula de exorcismo e faz o sinal da cruz na fronte, pronuncia uma fórmula trinitária e faz uma oração. Após, realiza a imposição do sal e novamente um exorcismo. $\bigcirc$ convertido torna-se um candidato ao batismo. Contudo, ele ainda não pode participar plenamente dos mistérios cristãos, sobretudo, da eucaristia. Após, ele se dirige a outra parte da igreja donde participa da assembleia cultual durante as leituras bíblicas.

O rito de iniciação prossegue com a preparação ao batismo (DUCHESNE, 1920, p. 315-322). Essa fase do rito destina-se à preparação dos catecúmenos. Ela se inicia no período da Quaresma. Diariamente, os candidatos recebem exorcismos (exceto nos domingos), instruções e passam pelo escrutínio (verificação da preparação ao batismo) e são impostas as mãos com sinal da cruz sobre os catecúmenos. Leem-se os relatos do Evangelho, e eles são explicados. Nos domingos, ocorre a iniciação ao Evangelho, ao símbolo [Credo] e à oração. Anteriormente ao rito do batismo, acontecia o sétimo e último escrutínio e exorcismo, após ocorria o éfeta (Effeta), no qual o padre tocava com saliva acima dos lábios (narinas) e orelhas de cada candidato. Em seguida era requisitado que os catecúmenos tirassem suas roupas para receberem no peito e nas costas o óleo exorcizante, que é um momento

19 "L'entrée dans le catéchuménat est accompagnée des cérémonies suivant: l'exsufflation, avec une formule d'exorcisme; l'imposition de la croix sur le front; l'imposition du sel." (DUCHESNE, 1920, p. 313). (Tradução nossa). 
crítico da celebração no qual ocorria a renuncia a Satanás e a adesão a Jesus. Realizada essa parte, eles se apresentavam diante do padre e afirmavam a sua fé pronunciando o símbolo da fé (Credo). Para finalizar, eles se prostravam, realizava-se uma oração e eram dispensados.

Na semana da Páscoa, a igreja se preparava para o batismo com a bendição dos óleos santos (DUCHESNE, 1920, p. 323-326). Esse rito acontecia na Quinta-Feira Santa (quinta-feira anterior ao dia da Páscoa, durante a Semana Santa) com a consagração dos óleos que iriam ser utilizados no rito de iniciação. Eles eram dispostos em duas âmbulas distintas, uma contendo óleo puro, e outra, óleo perfumado. Os óleos consagrados na Quinta-Feira Santa eram usados no rito de iniciação ao batismo, na crisma e no rito da extrema-unção.

No Domingo da Páscoa, ocorria o rito do batismo (DUCHESNE, 1920, p. 326-332). Ele estava inserido dentro da Vigília Pascal, os catecúmenos ouviam a recitação das leituras bíblicas que os recordava da relação do ser humano com Deus, tratava-se de um momento de instrução suprema no qual se ascendia ao mistério da iniciação.

Chega-se ao momento de se dirigir ao local do rito batismal. Utiliza-se o exemplo da Basílica de São João de Latrão em Roma. A Basílica é a primeira igreja cristã em Roma e é até hoje Sé Episcopal do Papa. A ida ao batistério dá-se em procissão. $\bigcirc$ batistério está situado atrás da basílica, a procissão passa por um pórtico no qual está representada o texto bíblico da vinha do Senhor (Isaías 5). Ela se inicia ao serem carregadas duas velas por diáconos até o interior do batistério, que são dispostas em frente à piscina batismal. $\bigcirc$ cortejo processional posiciona-se perto da piscina e o papa ou bispo profere uma oração coletiva, seguida por uma oração em forma eucarística. A liturgia do século VII prevê que se interrompa a oração e que se realize, por três vezes, o sinal da cruz sobre a água do batismo. Após, os diáconos que traziam as velas na procissão descem à água enquanto o papa profere uma apelação, outros clérigos e padres auxiliam no batismo fora e dentro da piscina batismal. Ato contínuo, ele derrama uma âmbula de óleo em forma de cruz na água. Os neófitos, catecúmenos que receberão o batismo, despem-se de suas vestes e se aproximam da piscina. $\bigcirc$ arquidiácono apresenta um a um ao papa, que questiona os 
neófitos sobre o símbolo da fé (Credo). Depois de responderem afirmativamente, os neófitos imergem três vezes enquanto o papa pronuncia a fórmula batismal trinitária (Batizo-te em nome do Pai e do Filho e do Espírito Santo). Dentro da piscina, a água ficava no máximo à altura de uma pessoa adulta, os neófitos também podiam levar a água do batismo às suas cabeças.

Após o batismo, acontecia o rito da confirmação (DUCHESNE, 1920, p. 332-333). Os batizados dirigem-se até a Capela da Cruz, localizada atrás do batistério, para o recebimento da Consignatio. Antes de entrar à capela, os batizados se apresentam diante de um padre para receberem sobre a testa uma unção com óleo perfumado. Em seguida, eles recebem suas vestimentas de cor branca, podendo receber a ajuda do seu padrinho ou madrinha. Em grupos, eles se posicionam diante do papa que pronuncia a invocação do Espírito Santo, sendo, em seguida, realizado sob a fronte de cada um o sinal da cruz com um pouco de óleo e pronunciada a fórmula trinitária.

O rito de iniciação e batismo termina com o rito da primeira comunhão dos neófitos (DUCHESNE, 1920, p. 333-334). O cortejo retorna de forma processional ao interior da basílica, enquanto a schola cantorum entoa cantos, invocações e litanias. Durante o longo período do batismo, as litanias vão cessando quando a procissão se aproxima. No interior da baślica, o papa se posiciona no altar, e é entoado o Gloria in excelsis. Antes de o canto terminar, o papa abençoa a água, o leite e o mel que serão dados aos neófitos após a comunhão eucarística. Os neófitos participam pela primeira vez do mistério eucarístico. A festa batismal continua ao longo de toda a semana até o próximo domingo, os neófitos com suas vestimentas brancas participam todos os dias da missa e cantam durante as noites nas vésperas. Eles são conduzidos em peregrinação ao interior do batistério e da Capela da Cruz enquanto cantam.

\subsection{Transição do rito do batismo no interior da igreja}

Como já havia sido mencionado antes, no século VII, o batismo de crianças já é uma realidade no seio da igreja. Em relação ao lugar do batismo, Moraes (2009, p. 152) destaca que: "com a prática generalizada de batizar mais crianças que adultos, 
as piscinas e seus batistérios dão lugar a bacias, que mais tarde receberão o nome de 'pias batismais', colocadas à esquerda da entrada da igreja".

No século IV, em geral, as piscinas batismais eram amplas e rasas; no século $\mathrm{V}$, elas tenderam a ser menores, estreitas e mais profundas; no século $\mathrm{VI}$, possuíam forma de cruz; e, com o passar do tempo e a diminuição dos tamanhos da piscina, criaram-se blocos monolíticos de mármore para a realização do batismo - as pias batismais -. Isso reflete um crescimento do número de batismos de crianças e a diminuição do batismo de adultos, levando o espaço batismal, antes separado, a uma progressiva incorporação no interior do templo.

A partir da Idade Média, ocorre uma maior intensificação da incorporação do espaço batismal no interior da igreja (MORAIS LIMA, 2012, n.p.). No século XII, com o surgimento da arquitetura gótica, o uso de batistérios já havia caído em desuso, e o sacramento do batismo não era mais visto como rito de iniciação ao Cristianismo, como fora em época anterior. A partir disso, "o batistério migrou para dentro da igreja” (MORAIS LIMA, 2012, n.p.). "Na época gótica, o batistério entra para a igreja, porém fixado em uma capela logo depois da entrada principal" (MORAIS LIMA, 2012, n.p.). Atualmente, a tendência é conjugar e reunir três espaços: da eucaristia, do batismo e da Palavra em um mesmo lugar.

\subsection{O rito batismal nos escritos de Lutero}

No século XVI, eclode a Reforma Protestante (KIRST, 2004, p. 5). O significado do batismo enquanto rito de iniciação para o cristianismo possui profundo sentido para o reformador alemão Martinho Lutero, mas já havia perdido bastante o seu significado simbólico e ritual. Para ele, o batismo havia perdido seu caráter principal de exercício diário da fé e do qual emana a promessa da salvação (LUTERO, 1988, p. 375ss). No texto "Do Cativeiro Babilônico da Igreja”, Lutero [1988, p. 375ss] expressa sua compreensão acerca dos sacramentos, reduzindo-os de sete (07) para apenas dois (02): batismo e eucaristia. Não entraremos em todos os meandros dessa discussão, para tanto, basta saber que há essa diferença entre luteranos e católicos. 
Um fato que se destaca nesse texto é a ênfase dada por Lutero [1988, p. 380) na interpretação e vivência do batismo. Para ele, o batismo representa a submersão na água, que dá origem ao nome batismo, oriundo do grego, significando ainda o cumprimento da promessa batismal através da fé, que é representado através de um sinal concreto: "a submersão do velho ser humano e a emersão do novo ser humano" (LUTERO, 1988, p. 382). Destaca-se, sobretudo, o fato de Lutero (1988, p. 383; WILSON, 2014) ter optado pelo batismo de imersão frente à prática medieval do batismo de crianças e por aspersão. Para ele, o ideal seria usar água em abundância, na forma de imersão, porque isso representaria, em forma de sinal e de promessa, o verdadeiro significado do batismo. No entanto, tal prática nunca chegou a ser majoritariamente praticada pelos cristãos luteranos. ${ }^{20}$

Sobre a ordem do batismo, Lutero foi incisivamente instigado pelo pastor Nikolaus Hausman a redigir liturgias para as comunidades que haviam aderido à Reforma na Alemanha, mas hesitava em fazê-lo. Em 1523, ele começa a publicar alguns escritos litúrgicos. Ele publicou uma revisão do rito batismal - "The Order of Baptism $^{21}$ (LUTHER, 1965b, p. 95-103) -. É uma tradução do latim para o alemão da liturgia romana do batismo praticada em Wittenberg (Alemanha), com pequenas modificações. Ele eliminou alguns trechos do rito, sobretudo os exorcismos, e substituiu uma das orações por uma que ele próprio havia escrito, a oração Sintflutgebet (Inglês: Great Flood; Português: Oração do Dilúvio), na qual recuperava-se o significado da água a partir do contexto bíblico. Em suas próprias palavras a primeira revisão do rito do batismo não eliminava muito do rito "para não onerar as consciências fracas, deixo-o como está, para que não venham queixar-se de que eu estaria querendo instituir um Batismo novo, e critique as pessoas que foram batizadas até agora, afirmando que não teriam sido batizadas corretamente" (LUTERO, 2016, p. 217).

Lutero conservou em sua primeira versão os seguintes elementos:

20 “[...] gostaria eu que os que vão ser batizados fossem submergidos totalmente na água, tal como soa o vocábulo e designa o mistério. Não o julgo necessário, mas seria bonito dar a uma coisa tão perfeita e plena um sinal também pleno e perfeito, tal como Cristo, sem dúvida, o instituiu." (LUTERO, 1988, p. 383).

${ }^{21}$ Em português: "Manual do Batismo Traduzido para o Alemão". Trata-se da tradução para o alemão da liturgia católica utilizada na época de Lutero. (LUTERO, 2016, p. 210). 
[...] o suspiro sob os olhos, o sinal da cruz, a colocação do sal na boca, colocando a saliva e o barro nos ouvidos e no nariz, unção do peito e dos ombros com óleo, fazendo o sinal da cruz sobre a cabeça com o óleo da crisma, vestindo a veste do batismo, colocando uma vela acessa na mão. ${ }^{22}$ (LUTHER, 1965b, p. 95-103. WILSON, 2014).

Uma revisão mais profunda foi realizada na segunda ordem de batismo "The Order of Baptism Newly Revised (1526)" -. Nela, Lutero eliminou diversas partes da liturgia que não considerava essenciais. Segundo Susan C. Karant-Nunn (1997, p. 51), nessa revisão, mostrou-se "a ousadia e a força da convicção do reformador ${ }^{\prime 23}$. Ele transformou o epílogo da versão anterior no prólogo da nova ordem de batismo, eliminando a parte sobre não onerar as consciências fracas.

No rito do batismo, reteve partes da cerimonia católica, deixando somente o que julgava ser o essencial. Dessa forma, a ordem era constituída por um breve exorcismo seguido pelo sinal da cruz na fronte e no peito da criança, seguida por duas orações: na primeira, invocava-se a Deus que recebesse o neófito na graça do batismo seguida pela oração Sintflutgebet (Inglês: Great Flood; Português: Oração do Dilúvio) que terminava em um exorcismo com a invocação da trindade. O rito prosseguia com a leitura do Evangelho de Marcos (10.13-16), seguido por uma imposição de mãos sobre a cabeça da criança, ajoelhando-se durante a oração, oravase juntamente com os padrinhos e madrinhas a oração do Pai-Nosso. Em seguida, a criança era levada até o local batismal, no qual se proferia uma bênção e se pronunciava, através dos padrinhos e madrinhas, a renúncia ao diabo em forma de perguntas. Em seguida, a criança era batizada, mergulhando-a na água e proferindo a fórmula batismal trinitária. $\bigcirc$ batismo terminava com uma oração. Nesse momento, era vestida na criança uma roupa branca.

22 "[...] breathing under the eyes, signing with the cross, placing the salt in the mouth, putting spittle and clay into the ears and nose, anointing the breast and shoulders with oil, signing the crown of the head with the chrism, putting on the christening robe, placing a burning candle in the hand". LUTHER, 1965b, p. 95-103. WILSON, Sarah Hinlicky. Baptismal Liturgies in Lutheran History and Practice. Trilateral dialogue - January 2014. Disponível em: <http:/ / www.strasbourginstitute.org/wpcontent/uploads/2014/02/Baptismal-Liturgies-in-Lutheran-History.pdf>. Acesso em: 12 abr. 2016. (Tradução nossa).

23 "[...] the boldness and strength of the Reformer's conviction." (KARANT-NUNN, 1997, p. 51). (Tradução nossa). 


\section{A passagem material no rito de batismo cristão: conclusão e relação}

Cabem serem feitas algumas considerações sobre a dinâmica do rito na Idade Média. A diferença principal que se percebe, ligada à segunda hipótese, é que, com a assunção do cristianismo como religião oficial do Estado, o rito de iniciação ao longo dos séculos foi perdendo seu caráter de formação da identidade cristã no âmbito da igreja e da sociedade. A presunção de que todos fariam parte da religião cristã, isto é, a indiferença entre o "interior" e o "exterior" social, trouxe prejuízos para o rito. Nesse ponto, percebe-se que o espaço no âmbito do rito batismal foi muito atingido, ao mesmo tempo em que o espaço arquitetônico, artístico e material foi valorizado em outros aspectos, como por exemplo, na magnificência e arte presentes nas inúmeras catedrais e basílicas construídas ao longo de todo o período.

No artigo, valorizou-se a relação do espaço no âmbito do rito e na forma como ele se insere nele. $\bigcirc$ espaço sempre teve influência sobre o rito, mas a forma como ele foi sendo reduzido dentro do âmbito do rito batismal deixa claro que ele já não cumpre mais uma função clara de passagem material. A própria teologia pode ser responsabilizada em partes por esse reducionismo espacial no âmbito do rito do batismo. Na liturgia católica do batismo de adultos, a ligação ritual entre batismo e eucaristia foi continuada por certo período de tempo. Lutero, em sua época, recebeu uma sequência ritual já modificada por diversas razões, como exemplo, já não se previa a realização de um catecumenato, um período de margem, tampouco a crisma/confirmação após o rito de iniciação batismal, nem a realização da Eucaristia concomitante ao rito, como era praxe.

○ue é elencado certamente necessita ser aprofundado em uma pesquisa, aqui apresentam-se somente duas sequências rituais que oferecem um panorama sobre a situação da passagem material. Deve estar claro que o espaço no âmbito do rito foi sendo reduzido e reorganizado de forma sistemática por um grande período de tempo e por razões complexas. $\bigcirc$ que foi realizado aqui é a simples análise comparativa de dois exemplos. Dessa forma, elencam-se alguns fatores que contribuíram para o reducionismo da passagem material no seio do rito de batismo. 
a) Com a prática de batizar crianças, o período de preparação (catecumenato] torna-se um rito desassociado do rito do batismo, no qual a prática de exorcismos nas cerimônias pré-batismais dá a impressão de o rito do batismo ser a conclusão dos ritos de exorcismos. Esse período é caracterizado pela fase de margem descrita por Gennep, a sua redução reflete também a perda do caráter de passagem;

b) $\bigcirc$ fato de a teologia diferenciar sacramentalmente os ritos de iniciação fêlos constituírem-se em três momentos sacramentais distintos: "batismo (incluindo o rito pré-batismal, batismal e pós-batismal, excluindo a confirmação), confirmação ou unção episcopal/crisma, e primeira Comunhão. Eventualmente estes momentos tornaram-se três ritos distintos" (BURRESON, 2004, p. 220) ${ }^{24}$.

c) $\bigcirc$ debate de Agostinho sobre o batismo de crianças. Para ele, era importante batizar as crianças devido à mortalidade infantil e, ao mesmo tempo, as preocupações teológicas que advinham do não recebimento do batismo, pois se queria garantir que a criança recebesse, através do batismo, o perdão dos pecados e a vida eterna. No entanto, isso reflete que a associação existente entre o momento do batismo na Vigília Pascal é desconectada de seu momento oportuno e significativo. Muitas vezes, tal batismo era praticado fora do âmbito do culto (em privado), em geral, dentro da igreja, sendo que somente havia a participação do neófito, dos pais (normalmente a mãe), parentes e amigos do casal, podendo contar com a presença do pai da criança (BURRESON, 2004, p. 221).

d) A desassociação entre a prática eucarística e o batismo encontra-se ligada à questão levantada no item $b$. A prática normal seria a realização da eucaristia logo após o batismo, mas, em virtude de a crisma ser o fechamento do rito do batismo e por ter sido delegada somente ao bispo, acabou-se firmando como um rito à parte do batismo. Logicamente, isso teve reflexos na prática batismal e no rito da

24 "[...] baptism (including the prebaptismal, baptismal and postbaptismal rites, excluding confirmation), confirmation or episcopal anointing/chrismation, and first Communion. Eventually these sacramentals moments became three distinct rites". BURRESON, Kent J. Water Surrounded by God's Word: The Diocese of Breslau as a Window into the Transformation of Baptismal from the Medieval Period to the Reformation. In: MAAG, Karin; WITVLIET, John D. (Eds.). Worship in medieval and early modern Europe. change and continuity in religious practice. Notre Dame, Ind.: University of Notre Dame Press, 2004. p. 220. (Tradução nossa). 
eucaristia. A eucaristia foi postergada por um período de tempo ou até mesmo por anos, isso já ocorre a partir do século VII, sobretudo, no batismo de crianças (BURRESON, 2004, p. 221).

As liturgias católicas e evangélicas são herdeiras do rito oriundo da Idade Média e também dos períodos anteriores. Por terem herdado muitos elementos que também já não estavam mais em prática na Idade Média, elas também já não expressavam mais a ligação ritual do batismo e da eucaristia, como expressa o rito batismal da diocese de Breslau, de 1535 (BURRESON, 2004, p. 224)25. A relação entre o rito e o espaço acabou perdendo sua importância durante a Idade Média, tanto no contexto da igreja protestante, quanto da igreja católica. Isso revela que o rito que se seguiu em inúmeras igrejas foi sendo reduzido e separado com o surgimento e os aprofundamentos de outros ritos e dos próprios sacramentos.

e) A narrativa mítica também pode ser incluída nesse processo de reducionismo da passagem material. Como foi afirmado anteriormente, a narrativa faz parte do ritual. Dessa forma, basta lembrar que, até a Reforma Protestante, era comum o uso da língua latina na realização dos ofícios da igreja. Como em grande parte, as pessoas eram iletradas e não compreendiam o latim, a narrativa também atuou como um fator de reducionismo do rito. A sua recuperação, após a Reforma, apresenta-a como uma dimensão importante da experiência ritual, não somente por causa da pregação, mas também para apreender o conteúdo ritual e bíblico. Mesmo que Lutero tenha diminuído bastante a liturgia do batismo em seu caráter de passagem material e de iniciação, por outro lado, ele valorizou a experiência da narrativa mítica.

Sob a ótica do rito e da discussão que foi promovida anteriormente, a redução do componente material ou da passagem material implica também a perda de uma maior síntese que o ser humano pode realizar no espaço. Uma perda mnemônica, pois não há mais a ligação entre o rito e o espaço de forma a expressar a margem ou o limiar ritual. A narrativa mítica, que fundamenta a ação cristã ritual

${ }^{25}$ BURRESON, 2004, p. 224. O autor analisa comparativamente o rito do batismo da Diocese de Breslau situada no ducado da Silésia, nesse período parte do Sacro Império Romano-Germânico, com o rito do século XIV do ano de 1524 e após a eclosão da Reforma o rito de 1535. 
no espaço, atua no sentido de fundamentar o rito e o uso do espaço, sua não apreensão por todos reduziu a capacidade de síntese espacial.

\section{Conclusão}

Turner (1974, p. 29), que deu seguimento ao trabalho de Gennep, escreveu:

No contexto ritual ndembo, quase todo objeto, todo gesto realizado, todo canto ou prece, toda unidade de espaço e tempo representa, por convicção, alguma coisa diferente de si mesmo. É mais do que parece ser, e frequentemente, muito mais. Os ndembos têm noção da função simbólica ou expressiva dos elementos rituais.

E Isin (2006, p. 604) sobre o conceito de espaço no Cambridge Dictionary of Sociology. "Em outras palavras, o espaço importa. Mas, ele importa de uma forma mais complexa do que ele aparenta $[\ldots]^{m 26}$. Tais afirmações impõem um desafio ao pensamento que conecta as duas formas rituais acima descritas. Ambas possuem suas justificativas e suas razões, ambas possuem seus simbolismos e suas ações rituais. No entanto, pode-se fazer um questionamento para a atualidade: os cristãos utilizam toda a carga simbólica de seus elementos rituais?

É possivel perceber um reducionismo no ritual de batismo a partir da Idade Média. As várias modificações e as reformas implementadas representam, ao mesmo tempo, um sinal de inovação e adaptação ao contexto de sua época e a perda de inúmeros simbolismos e linguagens rituais que são caros para o contexto religioso. Enquanto a arquitetura das igrejas ganhou inúmeras catedrais e tornou-se mais bela e sofisticada, ressaltando-se o aspecto liminar ou de margem que representa o culto cristão, os ritos, sobretudo, o batismo como iniciação ao cristianismo, acabaram perdendo sua importância de agregação ao Corpo de Cristo e da igreja, ou seja, de passagem material que leva ao interior do mistério da igreja.

Nesse sentido, o questionamento que se coloca é altamente válido. As hipóteses levantadas se guiaram a partir do pensamento de Gennep. A passagem

26 "In other words, space matters. But it matters in a more complex way that it appears [...]". ISIN, Engin. Space. In: TURNER, Bryan (ed.). The Cambridge Dictionary of Sociology. Cambridge: Cambridge University Press, 2006. p. 604. (Tradução nossa). 
material precisa ser investigada de forma ainda mais profunda para demonstrar a profunda relação do espaço no âmbito do rito. A afirmação de Isin reflete que a pesquisa necessita olhar com atenção essa área e sua relação com o rito. Pois, como ele afirma, o espaço importa, e ele é muito mais importante e complexo do que aparenta ser.

\section{Referências}

ALMEIDA, Francisca Pires de. $\bigcirc$ ritual do batismo em Portugal na Baixa Idade Média e nos inícios do século XVI. Medievalista online, Porto, n. 16, p. 01-28, 2014.

ASSMANN, Aleida. Erinnerungsräume. Formen und Wandlungen des kulturellen Gedächtnisses. München: Beck, 1999.

BIERITZ, Karl-Heinrich. Fundamentação antropológica. In: SCHMIDT-LAUBER, HansChristoph; MEYER-BLANCK, Michael; BIERITZ, Karl-Heinrich (Eds.). Manual de Ciência Litúrgica: ciência litúrgica na teologia e prática da igreja. v. 1. São Leopoldo: EST/Sinodal, 2011. p. 144.

Gedächtnis des Glaubens. Das Kirchenjahr vor den

Herausforderungen der Gegenwart. Vortrag von Herrn Prof. Dr. Karl Heinrich Bieritz am 13. November 2009 im Religionspädagogisches Institut Loccum während des „Treffpunkt Kirchenpädagogik“ gehalten. Disponível em: <http:/ / www.rpiloccum.de/ material/ audio-vortraegel?page=5>. Acesso em 20 mai. 2014.

BRANDT, Olof. Understanding the structures of Early Christian Baptisteries. In: HELLHOLM, David; VEGGE, Tor; NORDERVAL, Øyvind et al. (ed.), Ablution, initiation, and baptism: late antiquity, early Judaism, and early Christianity. vol. I. Berlin: Walter de Gruyter, 2011.

BURRESON, Kent J. Water Surrounded by God's Word: The Diocese of Breslau as a Window into the Transformation of Baptismal from the Medieval Period to the Reformation. In: MAAG, Karin; WITVLIET, John D. (Eds.). Worship in medieval and early modern Europe. change and continuity in religious practice. Notre Dame, Ind:: University of Notre Dame Press, 2004.

BUSCH, Kathrin. Kraft der Räume. In: ERNE, Thomas; SCHÜZ, Peter. Die Religion des Raumes und die Räumlichkeit der Religion. Göttingen: Vandenhoeck \& Ruprecht, 2010.

CASSIRER, Ernest. Antropologia Filosófica. Ensaio sobre o homem, introdução a uma filosofia da cultura humana. São Paulo: Editora Mestre Jou, 1972. 
DUCHESNE, Louis. Origines du culte chrétien : étude sur la liturgie latine avant Charlemagne. Paris: A. Fontemoing, 1920.

FREITAS, Valdemar de. Anatomia. Conceitos e Fundamentos. Porto Alegre: Artmed, 2008.

GENNEP, Arnold van. Os ritos de passagem: Estudo sistemático dos ritos da porta e da soleira, da hospitalidade, da adoção, gravidez e parto, nascimento, infância, puberdade, iniciação, ordenação, coroação, noivado, casamento, funerais, estações, etc. 3. ed. Petrópolis: Vozes, 2011.

ISIN, Engin. Space. In: TURNER, Bryan (ed.). The Cambridge Dictionary of Sociology. Cambridge: Cambridge University Press, 2006.

JOHNSON, Maxwell E. The rites of Christian Initiation. their evolution and interpretation. 2nd, rev. and expanded ed. Minnesota: Pueblo Book, Liturgical Press, 2007.

KARANT-NUNN, Susan C. The Reformation of Ritual. An Interpretation of Early Modern Germany. London/New York: Routledge, 1997.

KIRST, Nelson. Construir e reformar igrejas: o que sua comunidade deveria saber. Tear. liturgia em revista, São Leopoldo, n. 14/15, p. 3-19, out. 2004.

LÖW, Martina. Raumsoziologie. 8. Auflage. Frankfurt am Main: Suhrkamp, 2015.

LUKKEN, Gerard. Rituals in abundance. critical reflections on the place, form, and identity of Christian ritual in our culture. Leuven: Peeters, 2005.

LUTERO, Martinho. Do Cativeiro Babilônico da Igreja. In: LUTERO, Martinho. Obras Selecionadas. v. 2. São Leopoldo: Sinodal; Porto Alegre: Concórdia, 1988.

O Manual do Batismo traduzido para o Alemão Revisado (1526). In: LUTERO, Martinho. Obras Selecionadas: vida em comunidade. v. 7. São Leopoldo: Sinodal; Porto Alegre: Concórdia; Canoas: Ulbra, 2016.

LUTHER, Martin. The Order of Baptism (1523). In: LUTHER, Martin. Luther's Works. Liturgy and Hymns. v. 53. Saint Louis: Concordia Pub. House; Minneapolis: Fortress Press, 1965b.

. The Order of Baptism Newly Revised (1526). In: LUTHER, Martin. Luther's Works. Liturgy and Hymns. v. 53. Saint Louis: Concordia Pub. House; Minneapolis: Fortress Press, 1965a.

MAUSS, Marcel. Review of Les Rites de Passage. L'année Sociologique, Paris, v. 11, p. 200-202, 1909. 
MESLIN, Michel. A experiência humana do divino: fundamentos de uma antropologia religiosa. Petrópolis: Vozes, 1992.

MORAES, Francisco Figueiredo de. O espaço do culto à imagem da lgreja. São Paulo: Loyola, 2009.

MORAIS LIMA, Marco Antonio. O espaço celebrativo segundo a imagem da igreja. Contemplação: revista acadêmica de filosofia e teologia da Faculdade João Paulo II, Marília, n. 1, n.p., 2010. n.p. Disponível em:

<http:/ / fajopa.com.br/ contemplacao/index.php/revista/article/view/8/9>. Acesso em: 10 dez. 2014.

SMITH, Jonathan Z. To take place: toward theory of ritual. Chicago: University of Chicago Press, 1987. p. 22.

STAUFFER, S. Anita. Problemática contemporánea de la arquitectura eclesial e la cultura. In: STAUFFER, S. Anita (Ed.). Dialogo entre culto y cultura. Ginebra: Federación Luterana Mundial, 1994.

TUAN, Yi-Fu. Espaço e lugar. a perspectiva da experiência. São Paulo: DIFEL, 1983.

TURNER, Victor. O processo ritual. estrutura e anti-estrutura. Petrópolis: Vozes, 1974.

WERTHEIM, Margaret. Uma história do espaço de Dante à internet. Rio de Janeiro: Zahar, 2001.

WILSON, Sarah Hinlicky. Baptismal Liturgies in Lutheran History and Practice. Trilateral dialogue - January 2014. Disponível em: <http:/ / www.strasbourginstitute.org/ wp-content/ uploads / 2014/ 02 / BaptismalLiturgies-in-Lutheran-History.pdf>. Acesso em: 12 abr. 2016. 